\title{
EL LIDERAZGO SITUACIONAL Y EL PODER
}

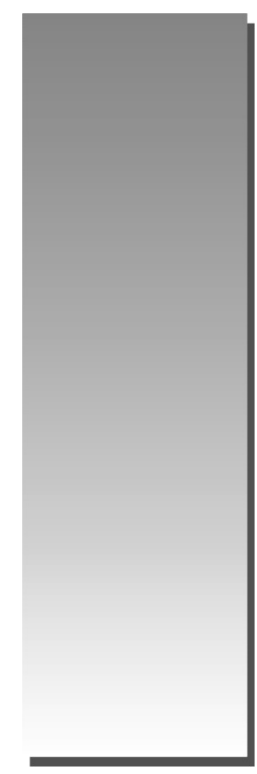

José Domingo Begazo*

d180045@mixmail.com

\section{RESUMEN}

Puede decirse que el liderazgo es el conjunto de capacidades que un individuo tiene para influir en un colectivo de personas, haciendo que este colectivo trabaje con entusiasmo en el logro de objetivos comunes. Se entiende como la capacidad de tomar la iniciativa, gestionar, convocar, promover, incentivar, motivar y evaluar a un grupo o equipo. En la administración de empresas, el liderazgo es el ejercicio de la actividad ejecutiva en un proyecto, de forma eficaz y eficiente, sea este personal, gerencial o institucional (dentro del proceso administrativo de la organización).

\begin{abstract}
It can be said that leadership is the skill set that an individual has to influence a group of people, making this group work with enthusiasm in achieving common goals. Is defined as the ability to take initiative, manage, hold, promote, encourage, motivate and evaluate a group or team. In business management leadership is the exercise of executive activity in a project effectively and efficiently, whether personal or institutional management (within the organization's administrative process).
\end{abstract}

Keywords: Leadership, puts, enterprise world, to be able expert.

* Doctor en Administración, Licenciado en administración de Empresas Cooperativas, Docente principal de la UNMSM, Decano de la Facultad de Ciencias Administrativas de la UNMSM. 


\section{LAS BASES DE PODER DEL LÍDER}

Puesto que el liderazgo es definido como el proceso de influencia en los comportamientos de los otros en vista de un objetivo determinado, el líder debe utilizar el poder a fin de lograr ejercer esta influencia.

Paul Hersey define el poder como el potencial de influencia del líder, el recurso que le permite influencia a sus empleados.

Este autor define siete bases del poder que pueden ser utilizadas por el líder:

1. El poder de coerción basado en el temor. Los empleados consienten a las demandas del líder porque temen represalias tales como la reprimenda y el despido.

2. El poder de relación (connection power) fundado sobre las relaciones que mantiene el líder con personas importantes o influyentes de las cuáles el empleado desearía obtener los favores.

3. El poder experto depende de las capacidades, de los conocimientos y de las habilidades de experto que posee el líder y que generan el respeto de los empleados. Estos lo respetan porque perciben, en sus capacidades, un recurso que puede ser útil en su trabajo.

4. El poder de información está basado en el acceso a las informaciones que posee el líder, de la cual necesitan los empleados.

5. El poder legítimo fundado en el puesto mismo del líder que le permite influenciar a los otros, porque ellos le reconocen el derecho, por su cargo, de esperar que ellos consientan a sus demandas.

6. El poder de referencia (referent power) basado en los rasgos de personalidad del líder. Los empleados son influenciados por el líder porque ellos lo quieren, lo admiran o se identifican con él.

7. El poder de recompensa fundado en la capacidad que tiene el líder de recompensar los comportamientos de los otros a través de incentivos, tales como remuneración, reconocimientos, promociones.

\section{BASES DEL PODER Y NIVEL DE MADUREZ}

Ninguna de estas bases de poder es eficaz en todas las situaciones.

Así, teóricamente, el líder debe elegir la base de poder a utilizar en función de la naturaleza específica de la situación.

P. Hersey postula que la eficacia de las diversas bases de poder depende de forma significativa del grado de madurez del empleado.

En consecuencia, el líder debe elegir no solo su estilo de liderazgo sino también la base de poder a ejercer, según el grado de madurez del empleado en una situación determinada.

El siguiente cuadro ilustra la relación que el autor establece entre la base del poder apropiada y el grado de madurez.

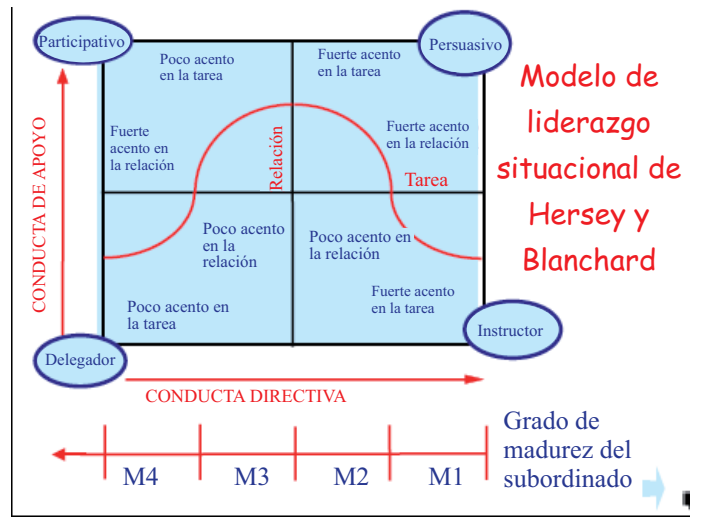

\section{BASES DE PODER, NIVEL DE MADUREZ Y ESTILO DE LIDERAZGO}

\section{EL PODER DE COERCIÓN}

Cuando el empleado se sitúa a un bajo nivel de madurez (M1: incapaz y no preparado), el estilo apropiado es E1 (informar o dirigir).

Ese estilo directo puede ser reforzado a través de la utilización del poder de coerción puesto que la amenaza de sanciones puede llevar al "seguidor" a aceptar las exigencias del líder.

\section{EL PODER DE RELACIÓN}

Cuando el empleado se sitúa en un nivel de madurez entre M1 y M2, es necesario combinar los estilos E1 (informar-dirigir) y E2 (persuadir).

El poder de relación puede reforzar esos dos estilos, llevando al empleado a aceptar las demandas del líder a fin de evitar las sanciones o para obtener las recompensas vía la persona influyente con la cual el líder está relacionado. 


\section{EL PODER DE RECOMPENSA}

Para el empleado de un nivel de madurez entre bajo y moderado, el estilo de liderazgo E2 (persuadir) puede ser reforzado por el poder de recompensa.

En este nivel de madurez, el empleado está listo a probar nuevos comportamientos.

Si se da cuenta que el líder está en condiciones de recompensar esos comportamientos, existe la posibilidad que consienta las demandas del líder, y este puede, a su vez, reforzar el crecimiento en el sentido deseado.

\section{EL PODER LEGÍTIMO}

Los estilos de liderazgo eficaces cuando el empleado se sitúa en un nivel moderado de madurez (M2 y M3) son los estilos E2 (persuadir) y E3 (participar).

El poder legítimo apoya esos dos estilos.

En ese nivel de madurez el empleado acepta o es influenciado por el líder en virtud de la posición de líder en la jerarquía de la organización, es decir, que el poder del líder es percibido como legítimo.

\section{EL PODER DE REFERENCIA}

El empleado del cual el nivel de madurez se sitúa entre moderado y elevado (M3) no tiene necesidad de mucha dirección, pero requiere aún mucho apoyo y comunicación del líder.

El estilo de liderazgo E3 (participar) apropiado a este nivel de madurez, será más eficaz si el líder tiene poder de referencia.

Cuando una persona es capaz pero no está preparada, el poder de referencia constituye un buen medio de darle confianza y de proporcionarle el aliento y el apoyo necesario.

El empleado tenderá a reaccionar positivamente y a aceptar la influencia del líder porque lo aprecia o lo admira o porque se identifica con él.

\section{EL PODER DE INFORMACIÓN}

Los estilos de liderazgo eficaces respecto al empleado que se sitúa en un nivel de madurez por encima de la media (M3 y M4) son los estilos E3 (participar) y E4 (delegar).

El poder de información es eficaz en ese nivel, porque el empleado espera que el líder le provea las informaciones que le permitirán mantener o mejorar su rendimiento.
Por otra parte, el hecho de saber que el líder está disponible para proporcionar las informaciones puede facilitar el crecimiento de la madurez del empleado.

\section{EL PODER EXPERTO}

El empleado que manifiesta un alto grado de madurez (M4) está a la vez preparado y posee la capacidad de asumir sus responsabilidades y responder mejor al estilo E4 (delegar).

La influencia del líder respecto a una persona tal vendrá del hecho que ella respeta las capacidades y las habilidades del líder en los dominios que ella percibe como importantes.

Observemos que Hersey hace una distinción entre el hecho de obtener el consentimiento del empleado y el hecho de influenciarlo.

Él considera que el líder pone el acento sobre el consentimiento con los empleados cuyo grado de madurez supera la media.

Las bases de poder apropiadas para obtener el consentimiento de personas de un bajo nivel de madurez (poder de coerción, de relación, de recompensa) tienden a ser apropiadas para influenciar las personas de un nivel elevado de madurez (poder de referencia, de información, experto).

\section{ESTILO Y ROLES DE LÍDERES}

LEADER / LÍDER, CONDUCTOR, DIRECTOR, GUÍA, JEFE.

Def. 1.: Es la capacidad adquirida y ejercida de influir en los demás. No es ciertamente la influencia del poder, que supone la desigualdad entre quienes mandan y quienes obedecen. Es más bien la influencia entre quienes son y se sienten iguales.

EL CAMINO DEL LÍDER. DAVID FISCHMAN. UPC EL COMERCIO. PÁG. 7.

Def. 2.: Persona que, en un determinado momento y lugar, a través de su conducta modifica, dirige o controla las actitudes y comportamientos de otras personas, a las que se denomina seguidores.

BUSINESS. AÑO V. N* 42. PÁG. 28 DE MARZO DE 1998.

\section{LEADER AUTOCRATIC / LÍDER AUTOCRÁTICO}

Individuo que controla a sus empleados a través del dominio y del poder inherentes a su cargo. 


\section{EMERGENT LEADER / LÍDER EMERGENTE}

Líder que sobresale de un grupo. Persona que representa las actitudes del grupo, sus valores, creencias y opiniones.

\section{INFORMAL LEADER / LÍDER INFORMAL}

Aquel cuyo poder e influencia sobre un grupo se deduce a partir de su aceptación por él mismo, más que por su importancia, posición, estatus o rango en la cadena de mando de una organización.

\section{SITUATIONAL THEORY OF LEADERSHIP / TEORÍA SI- TUACIONAL DEL LIDERAZGO}

Según ella, antes de elegir un estilo, los líderes deben comprender su propio comportamiento, el de sus subordinados y las necesidades de las tareas. Tal comprensión requiere habilidad analítica del comportamiento humano.

\section{AUTHORITARIAN LEADERSHIP / LIDERAZGO AUTORI- TARIO (1)}

Liderazgo absoluto, a través del cual la persona investida de autoridad establece todas las metas y todos los caminos para lograrlas, asigna las funciones, ordena los procedimientos, dirige, evalúa y corrige el trabajo hasta en sus más pequeños detalles.

\section{EXPLOITATIVE AUTHORITATIVE LEADERSHIP STYLE / LIDERAZGO AUTORITARIO (2)}

Estilo básico de liderazgo en el cual la dirección muestra poca confianza en sus subordinados. La toma de decisiones es, por ello, muy centralizada.

\section{ACTION CENTERED LEADERSHIP / LIDERAZGO CEN- TRADO EN LA ACCIÓN}

Sistema de formación basado en la creencia de que los líderes se hacen, no nacen. Fue desarrollado por Jhon Adair y afirma que las necesidades básicas de un líder son menos importantes que sus acciones, como medida de la efectividad.

\section{DEMOCRATIC LEADERSHIP / LIDERAZGO DEMOCRÁ- TICO}

Liderazgo participativo, en el que el líder intenta apoyar y ayudar a los trabajadores a alcanzar sus objetivos:

1. Pidiendo la máxima iniciativa y participación de los miembros en decidir y llevar a cabo ciertas políticas,

2. Delegando su autoridad y estableciendo una relación cercana con sus miembros,

3. Motivando y promocionando a sus subordinados.

\section{DIRECTIVE LEADERSHIP / LIDERAZGO DIRECTIVO}

Estilo de dirigir un grupo de actividades centradas en un líder. Este toma la mayoría de las decisiones, orientadas en un cometido, y deja poca libertad de acción a sus subordinados.

\section{DISTRIBUTIVE LEADERSHIP / LIDERAZGO DISTRIBU- TIVO}

Proceso de compartir o delegar los roles y las responsabilidades del liderazgo con otros miembros del grupo.

\section{INSTRUMENTAL LEADERSHIP / LIDERAZGO INSTRU- MENTAL}

Estilo que se caracteriza por directivos que planean, organizan, controlan y coordinan las actividades de los subordinados para conseguir los objetivos del departamento o grupo.

\section{CONTINGENCY THEORY OF LEADERSHIP / TEORÍA DEL LIDERAZGO POR CONTINGENCIA}

Concepto de liderazgo desarrollado por Fred Fiedler, según el cual el estilo orientado hacia la labor es más productivo cuando la situación es muy incierta o muy definida. Cuando una situación no está clara, se recomienda un estilo moderado.

BUSINESS. AÑO V. N* 42. PÁG. 28 DE MARZO DE 1998.

\section{CONCLUSIONES}

1. El nuevo milenio ha transformado las prácticas de las organizaciones y con ello las habilidades y características que el nuevo entorno empresarial demanda de los líderes.

2. A los líderes del Siglo 21 se les exige una preparación diferente para poder atender las necesidades de las empresas modernas.

3. Conocimiento de más de un idioma, estudios universitarios, conocimientos de informática y capacidad de comunicación son algunos de los aspectos a tener en cuenta para ser líderes exitoso y competitivo.

4. El líder de hoy debe dominar un sinnúmero de funciones, que le faciliten interactuar con el medio y dirigir con eficiencia los destinos de la empresa. Deberá ser estratega, organizador y líder proactivo. Para poder organizar necesita saber hacia dónde va, cómo va a organizarse, y en cada etapa saber ser líder.

5. Deberá saber de todo un poco, y también conocer todos aquellos aspectos que pueden 
afectar una organización, estar preparado para enfrentarlo y ser consciente de que, a medida que avanza el tiempo, además de presentársele en el camino herramientas útiles para sobrellevar cualquier adversidad, aparecen también obstáculos que opacan el panorama.

6. Es entonces donde deberá demostrar que puede hacerle frente a todo eso y junto con el equipo humano que dirige enfrentarlo, contrarrestarlo, y aprender de ello para experiencias futuras.

\section{BIBLIOGRAFÍA}

Management Of Organizational Behavior - Hersey, Paul/ Blanchard, Kenneth H./ Johnson, Dewey E.

Servicio Situacional E Institucional (un Modelo Para Incrementar La Eficacia En El Servicio) - Editorial: Idh.- Año 1989 - Dr. Paul Hersey. ; Ing. Gustavo L. Ramírez. ; Dr. Tero J. Kauppinen. 